\title{
COMPLEMENTING ENGINEERING DESIGN USING DESIGN THINKING: AN ASSISTIVE TECHNOLOGY APPROACH
}

Luiz Fernando de Carvalho Botega (lfbotega@gmail.com) - Departamento de PósGraduação em Engenharia Mecânica, Universidade Federal de Santa Catarina

Tainá A. Bueno de Oliveira (tainabueno@gmail.com) - Departamento de Pós-Graduação em Design, Universidade do Estado de Santa Catarina

Diego de Castro Fettermann (dcfettermann@ gmail.com) - Departamento de PósGraduação em Engenharia de Produção, Universidade Federal de Santa Catarina

\section{RESUMO}

Product development in traditional engineering methodologies is usually a broad and intricate process, encompassing specific stages that are essential to the development, but oftentimes lacking the needed comprehension of the final user. On the other hand, Design Thinking (DT) is a still incipient methodology, though focused on enhancing innovation skills through a human-centered design approach to support decision-making. Both methodologies were designed for different contexts, each with specific benefits and limitations. With the increasing focus on innovation and the highly competitive market, aspects from both approaches can be combined to enhance the design practice. Such combination may serve as a catalyzer for innovation, reinforcing with traditional methodologies the solid base required in product/service development, but still reaching for DT heuristics and techniques to achieve better multidisciplinary teams, experimentation practices and a higher focus on users. This work intends to elucidate congruent aspects of both approaches to outline an integrative systematization. A literature review on the Ulrich and Eppinger methodology and three DT references was used as comparison basis for this work. By comparing and merging both paradigms, we propose a "hybrid" systematization, adapting aspects from both to reach a robust and adaptive model. The combined approach should be applicable to various contexts, using DT to broaden the use situations of traditional methodologies and ease the adaptation for unusual contexts in engineering design, such as assistive technology products. In this context, the processes used in a traditional engineering methodology and in DT were analyzed, exploring convergences and divergences that hint for gaps of intersection. In a comparative analysis, the methodologies are mutually complementary, converging for a flexible prescriptive proposition of the development process This becomes clear when comparing the proposed systematization to a specific methodology of assistive technology design, demonstrating the flexibility of the approach for reaching outlying contexts from the traditional methodologies. Due the high adaptive potential of the approach, the addition of concepts and heuristics of DT to traditional engineering methodologies may be able to reach many other unusual contexts, while still promoting competitiveness, innovation and a higher focus on the user.

Palavras chave: Design methodology; Design thinking; Assistive technology; Innovation Área: $O$ design e o desenvolvimento de produtos e serviços 


\section{INTRODUCTION}

Design methodologies are representations of New Products Development (NPD) process, aiming to aid future designers by using previous experiences and known structures (Ulrich and Eppinger, 2015). The use of methodologies for NPD is fundamental to the success of a product or service (Barczak and Kahn, 2012), offering a clear strategy of how NPD should work inside the organization and constantly improving its processes (Kahn et al., 2012). Predictive methodologies focus on a process-oriented paradigm with procedural and sequential stages that should be followed to achieve success (Clarkson and Eckert, 2010; Gericke and Blessing, 2011). Contrastively, the descriptive approach presents a more unconstrained methodology that uses product-oriented paradigm, which feeds from heuristics or "good practices" that were successful in the past and, therefore, may be of great help to other developments (Clarkson and Eckert, 2010; Gericke and Blessing, 2011).

Both approaches are beneficial and have specific niches of use. The first better ensures attention to important issues and leaves the decision process more explicit (Ulrich and Eppinger, 2015), while the second tend to be more flexible and user-centered (Brown, 2010). Naturally, most methodologies congregate aspects of both paradigms, but have different groundings (Clarkson and Eckert, 2010). The combination of both approaches may benefit the development process (Gericke and Blessing, 2011), using premises from both to create a combined model that is, at the same time, flexible and applicable to various scenarios, but robust and structured to improve design efficiency.

To study the impacts of such merging, we propose the combination of a traditional prescriptive methodology (Ulrich and Eppinger, 2015) to current descriptive Design Thinking (DT) models (Ideo, 2012; Gibbons, 2016), aiming for a hybrid systematization applicable to outlier contexts from traditional developments, such as assistive technology (AT) design. Being an extremely user-centered area, AT design is further from prescriptive models, but the inclusion of such principles may better solidify developments, using DT as an intermediate. To combine both approaches, we conducted a literature review aiming to identify conjoining factors. The proposed phases on the traditional methodology were contrasted to the DT model, evidencing intersections. As a result, the combined methodology emerged naturally, bringing the traditional methodology structure specially on latter phases of NPD, and using DT heuristics more intensely in during initial phases.

\section{METHODOLOGIES FOR NPD}

Current design teams are oftentimes requested to create new products or adapt current portfolio to fulfill market demands before competitors (Žnidaršič and Jereb, 2011). The needed quickness and technology complexity demand team effort, with various experts working simultaneously to reach solutions (Ulrich and Eppinger, 2015). With such group endeavor, problems of communication and organization arise, requiring design structure and methods to deal with interaction and knowledge share between experts from different fields (Stompff $e t$ al., 2016).

By dividing the design process into concise phases or tasks allows a heuristic vision and understanding of the process and its parts. Different methodologies arise to deal with such complexity, giving higher or lesser structure to the product development when needed. NPD is a process of information development needed to identify demand, production and use of a product (Back et al., 2008). From this understanding, two subdivisions can be used to understand extreme paradigms of product development (Korhonen, 2007; Back et al., 2008): 
- Prescriptive models: a set of structured formalizations of how a design process should be done, as a procedure of stages and activities;

- Descriptive models: composed of heuristics or "good practices", usually acquired by practical design experience in a certain field.

In the market, such paradigms are commonly combined to achieve solutions. Even in traditional engineering developments, prescriptive methodologies are adapted using the team members experience or know-how of the organization (Ulrich and Eppinger, 2015). Such models are excessively broad to many situations, but a company should be able to adapt and fit such methodologies to particular needs (Kahn et al., 2012). Prescriptive models tend to overlook the dynamic behavior of different developments, presenting phases with emphasis on what is required to be done rather than how it should be done (Gericke and Blessing, 2011). On the other hand, pure descriptive methodologies oftentimes leave too much decision to individual designers, which may hamper efficiency and knowledge transfer. Every organization and design team should have adaptations of a methodology, which can be suited to different project's particular nature (Kahn et al., 2012).

\subsection{ULRICH AND EPPINGER}

To reach economic success, most firms depend on their ability to identify the needs of customers and create, as quickly as possible, products that fulfill these needs and can be produced in a cost-effective fashion (Ulrich and Eppinger, 2015). To enhance success probability, different expertise should be merged to create a robust systematization for product development. In the method proposed by Ulrich and Eppinger (2015), a product development is subdivided in six generic phases (Figure 1).

Figure 1 - Predictive design methodology for NPD (Ulrich and Eppinger, 2015)
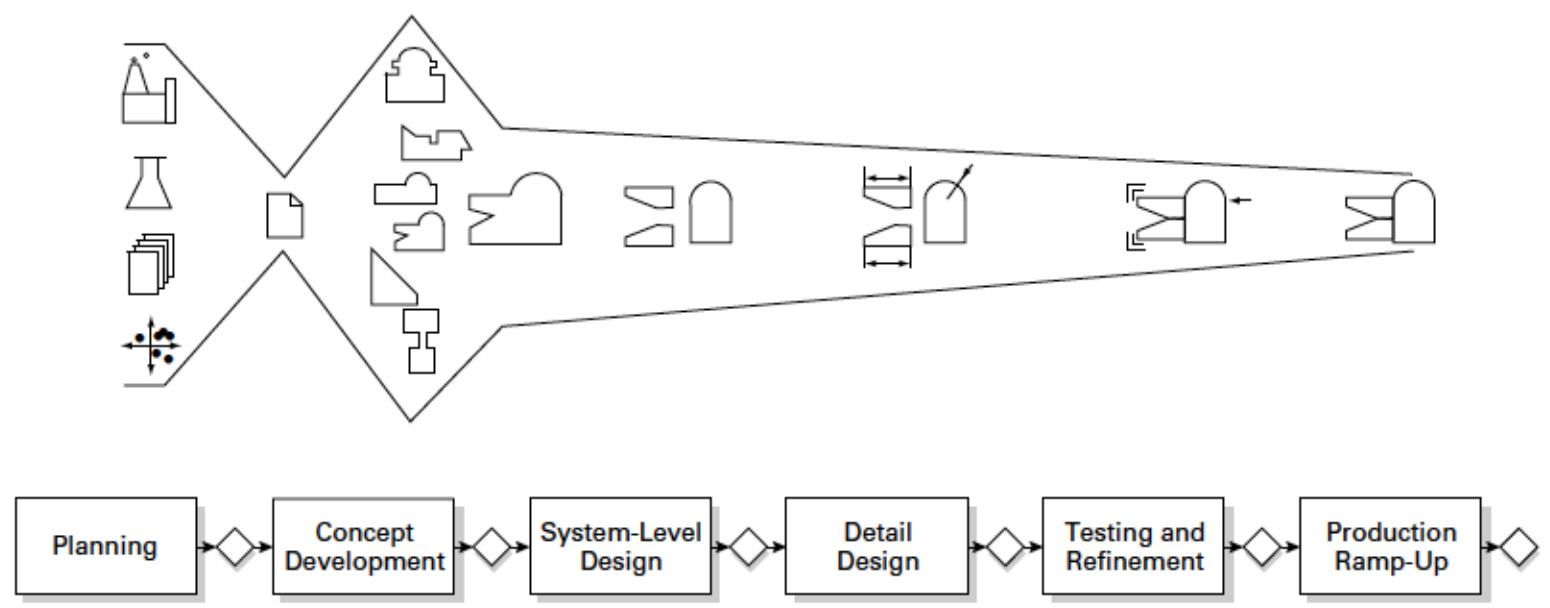

Planning it is "phase zero". In this, the cycle of the NPD is envisioned, involving areas from marketing, design, and manufacturing. The design team discuss about initial strategies and technology development opportunities, unexplored markets, objectives, company's portfolio, possible supply chains, planning goals and resources. The output of this phase is the project mission statement.

After the consolidation of the project's briefing begins the concept development, a phase of high ideation leading to possible solutions for the problem. Initial models and prototypes may aid in this stage and better guide the design to the following phase of system-level design. 
In this, the developed solutions are furtherly tested, including production possibilities, evaluation of components' architecture and materials, to reach a preliminary structure of the final solution. The following detail design finishes and define a solution that befits the initial briefing, specifying all materials, geometry, manufacturing plan and documentation control.

Testing and refinement introduces the final product into restricted markets or users to evaluate function and acceptance. This phase also refines the production process, including manufacturing and distribution. Such tests include internal and external validation, exploring improvement possibilities before the product launching. The last phase, product ramp-up consolidates the installation of manufacturing facilities, training of workforce, and mass distribution of the product.

\subsection{DESIGN THINKING}

The choice or adaptation of a design methodology to be used during NPD is deeply dependent on the design situation. Different design teams in different contexts may require a greater or lower structure to adequately develop solutions. Descriptive models may be used to ground prescriptive models (Gericke and Blessing, 2011), using the heuristics of the first to better suit the second into the teams' and potential users' reality.

"Good practices" or heuristics tend to arise from reoccurring patterns, which, in time, are absorbed by the design team and used as invisible guidelines for projects. DT, based on Human-Centered Design (Ideo, 2012) paradox, includes heuristics such as user-centered vision, co-working, iteration between ideation and prototyping, constant experimentation, intense use of visualization methods, optimism, risk-orientation, use of creativity techniques, and experience design focusing on emotional aspects (Brown, 2010). DT is a highly used approach on current market due to its flexibility and ability to reach higher levels of innovation (Dorst, 2011).

Despite the intention of late publications to add structure to DT, this model is still empirical and has no well-defined consensus. In general, most approaches present three distinct phases (Brown, 2010; Vianna et al., 2012; Ideo, 2015; Gibbons, 2016):

- Inspiration: comprehends iterative phases of discovery of design possibilities using of high empathy with users, followed by the definition or briefing of the problem to be solved;

- Ideation: starts with the conceptual ideation, using the acquired knowledge to develop and prototype ideas and solutions iteratively;

- Implementation: comprehends the testing of the solutions with final users (which may also be started previously during ideation) and implementation of the product in the market.

The creative aspect incurs thus in a flux and bottlenecking of ideas, which can be seen in Figure 2. This may induce the division of some phases into two: a divergence of ideas followed by a convergence to solutions. This pattern corroborates to the bottlenecking, firstly diverging design possibilities then converging to a briefing, followed by a second divergence of ideas and conceptions and a convergence to principles of solutions (Ideo, 2012). 
Figure 2 - Representation of the NPD process on DT (Ideo, 2012; Gibbons, 2016)

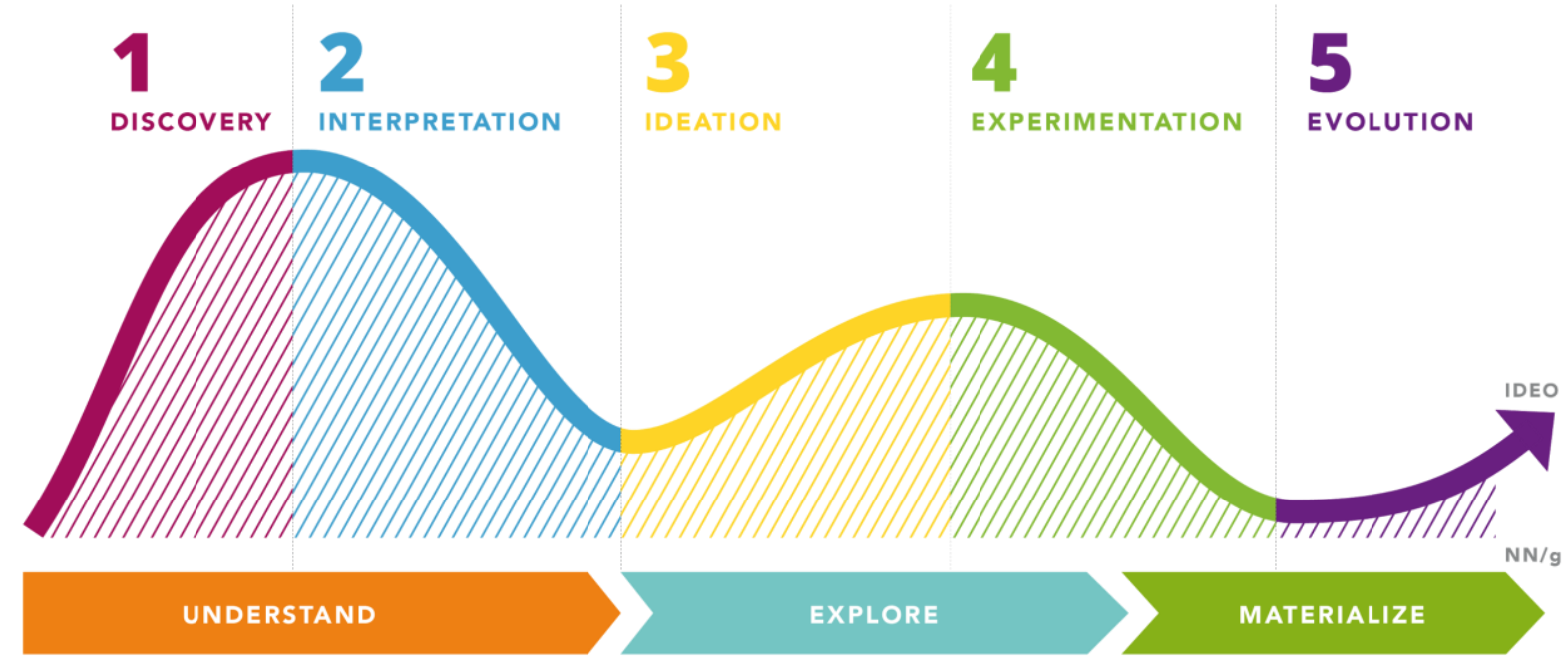

\section{MERGING APPROACHES INTO A HYBRID PROPOSITION}

Due to the traditional excellence on product development imbued on traditional engineering methodologies (usually prescriptive), these areas tend to give higher relevance to technical aspects and structure, oftentimes leaving users and empathy to the background. At the same time, design and architecture methodologies are centered in unstructured methods (usually descriptive), using heuristics as guidance for the process. Overly vague approaches tend to be incompatible with current market that demands high productivity and constant innovation, not allowing wastes of time that may result from unrestricted ideation and experimentation (Mostert, 2007).

This separation and bias between development methodologies is oftentimes counterproductive. The addition of DT heuristics into a traditional and structured methodology into a hybrid proposition may center benefits from both sides. The DT approach is more flexible and the user-centered behavior, which enhances the chance of a product success (Baxter, 2011), may help adapting traditional methodologies to a higher variety of scenarios. At the same time, the foundations of prescriptive models may add competitive edge and the structure required in current market.

In fact, both approaches are complementary. The here-presented proposition of a hybrid systematization, shown in Figure 3, combines aspects of the Ulrich and Eppinger (2015) methodology and DT principles (Ideo, 2012; Gibbons, 2016). While the first gives an overall view of the NPD, with high emphasis to documentation and technical aspects, the second deepens the exploratory and user-centered approach. The new systematization uses the backbone of engineering methodology, but adds the constant iterations from modern approaches and uses a human-centered paradigm to better explore the problem's briefing and conceptual ideation. 
Figure 3 - Hybrid methodology combining traditional methodology and DT.

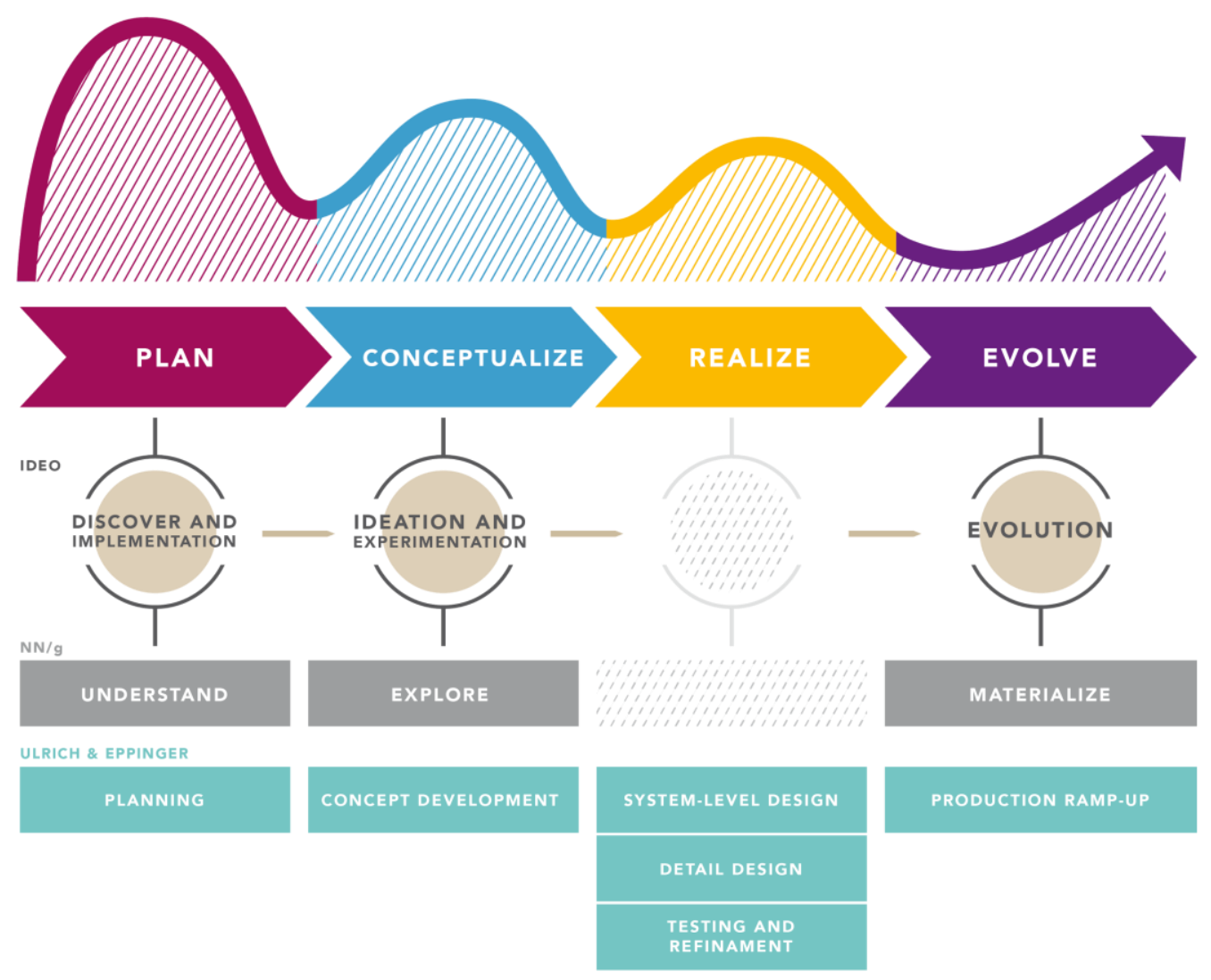

The four macro-phases incorporate aspects from both approaches, the first two leaning to DT heuristics, while the last two firmly based on the experience of traditional NPD processes:

- Plan: aims for the definition of the briefing, or the problem to be solved. By going through iterative phases of discovery and interpretation, the design team can empathize with users and stakeholders to better define the aim of the development. Naturally, such exploratory process should befit the organizational marketing plan and portfolio. This stage also includes the definition of management plan, chronogram, human resources, viability and feasibility of the project;

- Conceptualize: incorporates the ideation and experimentation phases of the project, dealing with ideas and conceptions to solve the previously stablished problem (briefing). This includes communication with customers, multidisciplinary interaction, knowledge acquisition, free ideation, synthesis and analysis of possible solutions, including the use of experimental models and prototypes to validate possible product's architecture. This stage aims for the definition of one or few solutions to be furtherly developed;

- Realize: develops aspects of engineering design aiming for component engineering, choice of materials, manufacturing (including tolerances), identification of suppliers, market analysis of solutions and overall narrowing to a single solution. The team should also address legal aspects, marketing strategy, test the performance and reliability of the product or service, possibly changing and combining solutions to adapt to inadequacies. At this stage, it is expected a defined solution that is feasible, viable and desirable;

- Evolve: initiates the pilot batch testing in the market, evaluating outcomes, goals and success indicators. In this evolutionary process, the solution may be tested in a 
restricted field before mass production to identify other changing possibilities that may lead to a more adequate product or service. When matured, the solution can be produced in a full-scale. Being a perpetual phase, the feedback acquired should retro-feed the process to generate improvements or to perceive changes on customer behavior that may lead to a new product;

\section{ADAPTATION TO ASSISTIVE TECHNOLOGY}

In the matter of NPD that attends to a public with disabilities, a movement known as Inclusive Design or Assistive Technology (AT) emerged, emphasizing the understanding of the users' diversity to cover their needs and aspirations. The inclusive design focuses on the impact of diversity of people on design decisions (Cambridge, 2017). AT devices and services were defined by the United States of America (2004) as a federal law in the Individuals with Disabilities Education Act, encompassing any tangible system, whether directly acquired, modified, or customized, that is used to better fit its functional capabilities to a person with a disability.

To achieve an accessible society, disabilities must be taken into account through the whole design process and the organization culture, nurturing the principle of Universalist philosophies like Universal Design (Plos et al., 2012). Design for All aims to enable all people to have equal opportunities to participate in every aspect of society. To achieve this, the built environment, everyday objects, services, culture, and information must be accessible, convenient for everyone in society to use and responsive to evolving human diversity. The concept of disability may have limited the understanding of the need for accessible technology (Stevenson and Mcquivey, 2003). Instead of assuming accessible technology as only useful to a distinct group of people with disabilities, the industry should consider a wide range of users who could benefit from such accessible technology, designing to achieve a more inclusive society.

In this study, the use of AT terminology is related to NPD processes that include the needs of disabled users. The inclusive design focuses on product design, market knowledge associated with user needs, and business viability to maximize product performance (Cambridge, 2017). A group from University of Cambridge led by Sam Waller developed an "Inclusive Design Toolkit" (IDT) to design products aimed at people with disabilities (Cambridge, 2017). The Toolkit consolidates fundamental questions of the concept design process into four spaces, as presented in Figure 4. The sequence should be implemented through cycles of exploring needs, creating concepts and evaluating options. Each phase includes several activities to keep on track better solutions, and it is vital to include early phases of evaluation to begin testing and adapting ideas to the users. 
Figure 4 - Inclusive Design Toolkit (Cambridge, 2017).

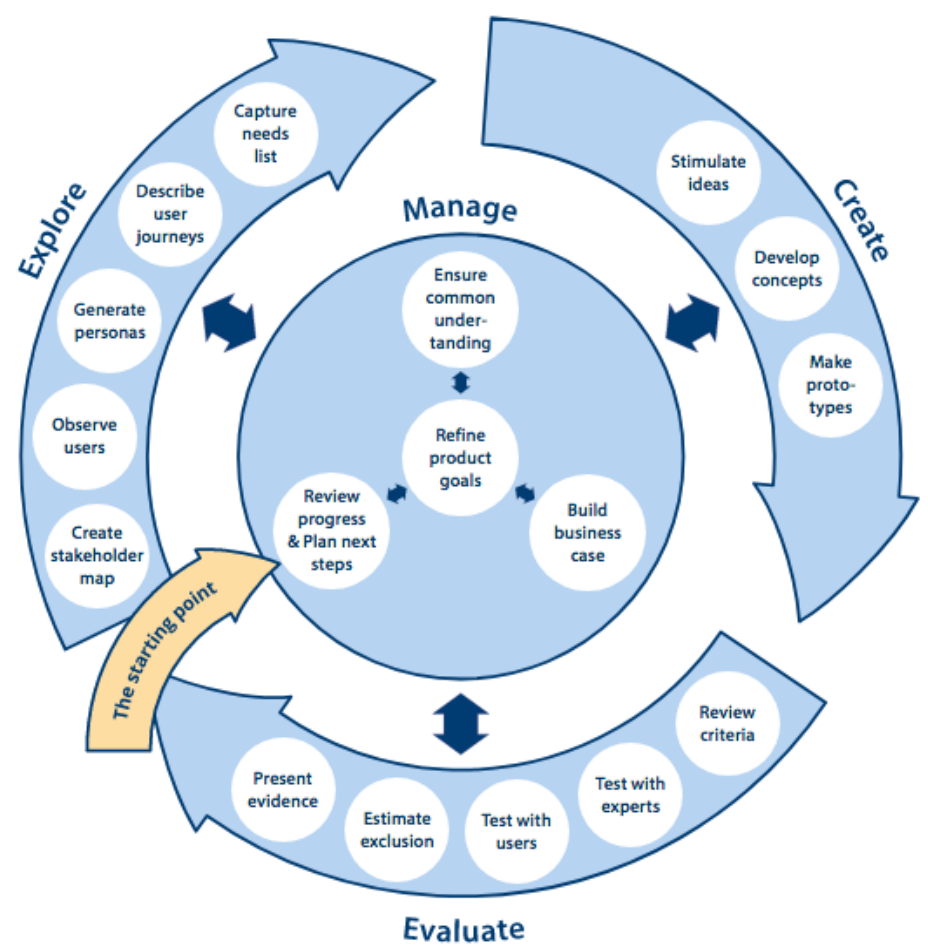

When comparing the AT methodology to the hybrid systematization proposed, both present a strong concern in questions related to the user-centered approach. While traditional engineering methodologies would require great adaptation to be used in such context, the hybrid proposition presents an easily adaptive structure. The phases that compose the proposition are similar to many outlier contexts that focus on human-centered design, including the AT methodology. As seen in Figure 4, the methodology also presents distinctive phases: Explore and Manage, similar to Plan on the hybrid model; Create, similar to Conceptualize; and Evaluate, similar to Evolve. The AT methodology also overlooks engineering definitions and manufacturing, aspect included in the proposed methodology. The intermediate phase of Realize may also benefit the design by offering more structure and by including tasks that are vital to a NPD. Overall, the use of the hybrid model might offer a needed emphasis in documentation and technical aspects the are lacking in the AT methodology.

\section{CONCLUSIONS AND FUTURE WORKS}

This preliminary work aimed for the intersection of two approaches used in NPD. The incorporation of current approaches used by design teams to solve problems into traditional and structured methodologies reveals an adaptive and more updated systematization (Gericke and Blessing, 2011). Both approaches present pertinent aspects and contributions to a better understanding on how to design. The hybrid model shows potential by being adaptive to scenarios distant to traditional methodology due to the use of DT, while still incorporating the structure present in approaches such as the Ulrich and Eppinger (2015) methodology.

As presented, AT lies in a more human-centered spectrum in which traditional methodologies may not be adequate. The bridge constructed using DT narrows this distance without compromising quality and formality of the NPD. The hybrid approach fits the methodology proposed for AT design, implying a flexibility potential to other outlier scenarios 
from traditional engineering methodologies.

Naturally, this work limits itself to the proposition of a hybrid approach, not deepening NPD aspects that would characterize a new methodology. The research also requires deepening and applications of the methodology in several scenarios to confirm adaptability and efficiency, culminating on a verified evolution of NPD process. Even so, the proposition serves as a starting point to discuss the need for renovation and propose changes on traditional methodologies still largely used throughout the world.

\section{REFERENCES}

AMERICA, U. S. O. Amendments to the Individuals with Disabilities Education Act. CONGRESS, U. S. O. A.: 162 p. 2004.

BACK, N. et al. Projeto Integrado de Produtos: Planejamento, Concepção e Modelagem. São Paulo: Manole, 2008. 601 ISBN 852042208X, 9788520422083.

BARCZAK, G.; KAHN, K. B. Identifying new product development best practice. Business Horizons, v. 55, n. 3, p. 293-305, 5// 2012. ISSN 0007-6813.

BAXTER, M. Projeto de Produto: Guia Pratico para o Design de Novos Produtos. 3rd. Edgard Blucher, 2011. 344 ISBN 9788521206149.

BROWN, T. Design Thinking - uma metodologia poderosa para decretar o fim das velhas ideias. Rio de Janeiro: Campus, 2010. ISBN 9788535238624.

CAMBRIDGE, U. O. Inclusive Design Toolkit. 2017. Disponível em: < http://www.inclusivedesigntoolkit.com/ > . Acesso em: 26 may 2017.

CLARKSON, J.; ECKERT, C. Design process improvement: a review of current practice. Springer Science \& Business Media, 2010. ISBN 1846280613.

DORST, K. The core of 'design thinking' and its application. Design Studies, v. 32, n. 6, p. 521-532, 11// 2011. ISSN 0142-694X.

GERICKE, K.; BLESSING, L. Comparisons of design methodologies and process models across disciplines: a literature review. International Conference on Engineering Design. Denmark. Vol. 1: Design Processes: 12 p. 2011.

GIBBONS, S. Design Thinking 101. 2016. Disponível em: < https://www.nngroup.com/articles/design-thinking/ >. Acesso em: 24 mar. 2017.

IDEO. Design Thinking for Educators: 81 p. 2012.

. The Field Guide to Human-Centered Design. California: IDEO, 2015. ISBN 9780991406319.

KAHN, K. B. et al. An examination of new product development best practice. Journal of Product Innovation Management, v. 29, n. 2, p. 180-192, 2012. ISSN 1540-5885.

KORHONEN, J. Environmental planning vs. systems analysis: Four prescriptive principles vs. four descriptive indicators. Journal of Environmental Management, v. 82, n. 1, p. 5159, 1// 2007. ISSN 0301-4797.

MOSTERT, N. M. Diversity of the Mind as the Key to Successful Creativity at Unilever. Creativity and Innovation Management, v. 16, n. 1, p. 93-100, 2007. ISSN 1467-8691.

PLOS, O. et al. A Universalist strategy for the design of Assistive Technology. International 
Journal of Industrial Ergonomics, v. 42, n. 6, p. 533-541, 11// 2012. ISSN 0169-8141. STEVENSON, B.; MCQUIVEY, J. L. The Wide Range of Abilities and its Impact on Computer Technology. A research study commissioned by Microsoft Corporation and cunducted by Forrester Research. Cambridge, MA. 2003

STOMPFF, G.; SMULDERS, F.; HENZE, L. Surprises are the benefits: reframing in multidisciplinary design teams. Design Studies, v. 47, p. 187-214, 11// 2016. ISSN 0142$694 X$.

ULRICH, K.; EPPINGER, S. Product Design and Development. McGraw-Hill Education, 2015. ISBN 9780078029066.

VIANNA, M. et al. Design Thinking: Inovação em negócios. Rio de Janeiro: MJV Press, 2012. 85 ISBN 978-85-65424-00-4.

ŽNIDARŠIČ, J.; JEREB, E. Innovations and Lifelong Learning in Sustainable Organization. Organizacija, v. 44, p. 10, 2011. 